\title{
Antioxidant activity and sensory evaluation of a cold dairy-based beverage enriched with Sargassum polycystum C. Agardh extract in sunflower oil
}

\author{
1,*Nurcahyanti, A.D.R., ${ }^{2}$ Melani, V., ${ }^{2}$ Pramitasari, R. and ${ }^{1}$ Notario, D. \\ ${ }^{I}$ Department of Pharmacy, School of Medicine and Health Sciences, Atma Jaya Catholic University of \\ Indonesia, Pluit Raya 2, 14440 Jakarta, Indonesia \\ ${ }^{2}$ Department of Food Technology, Faculty of Biotechnology, Atma Jaya Catholic University of Indonesia, \\ Raya Cisauk Lapan, Sampora, 15345 Banten, Indonesia
}

\section{Article history:}

Received: 14 April 2021

Received in revised form: 25

May 2021

Accepted: 13 June 2021

Available Online: 31

December 2021

Keywords:

Sargassum polycystum,

Fucoxanthin,

Antioxidant,

Functional drink

DOI:

https://doi.org/10.26656/fr.2017.5(6).264

\begin{abstract}
Natural based functional food and beverages have gained market interest in the last decade. Functional beverages, especially those enriched with nutrients and bioactive compounds, are of particular interest. Maintaining the nutritional or bioactive activity of these components along with their sensory attributes in the final product remains to be a challenge. Health benefits from bioactive substances, like fucoxanthin and phlorotannins, in marine algae makes it a promising commodity of an archipelago country. However, nutritional components, their stability, and an understanding of their nutritional and bioactive component availability require further investigation. Here we prospected natural and sustainable antioxidant additives from brown algae, Sargassum polycystum C Agardh, to enrich a cold dairy-based beverage. Food-grade extraction of $S$. polycystum was done by using $96 \%$ Ethanol to macerate dried powder algal. Identification of fucoxanthin in the extract was performed using High-Performance Liquid Chromatography (HPLC) (Prominance Shimadzu). We employed the 2,2-diphenyl-1-picrylhydrazyl method to quantify the antioxidant activity of extract alone and extract in three beverage formulations containing $0.02,0.05$, and $0.1 \mathrm{mg} /$ cup $S$. polycystum extract. Sensory evaluation and viscosity analysis comparing our product to the commercially available product was also performed. Results showed that the combination of $S$. polycystum extract with sunflower oil was able to maintain antioxidant activity when stored at $4{ }^{\circ} \mathrm{C}$. Formulation 2 of dairy-based beverages passed the sensory evaluation. This study was the first to report the application of S. polycystum extract on a cold dairy-based beverage. This product was developed considering the low stability of the bioactive compound, fucoxanthin. More comprehensive sensory evaluation and optimization for large scale production are highly required.
\end{abstract}

\section{Introduction}

In the past decade, there has been growing interest in the consumption of natural based-functional foods as they can potentially offer health benefits, such as reducing the risk of chronic diseases and improving the physiological conditions with almost no side effects (Ozen et al., 2012; Iwatani and Yamamoto, 2019; Jędrusek-Golińska et al., 2020). Functional food can be categorized into a whole, fortified, or enriched food and they can be consumed as part of the diet on a regular basis (Vicentini et al., 2016; Jędrusek-Golińska et al., 2020). The aim of this study was on the development of a functional beverage as it represents one of the largest and fastest-growing market sectors along with food and supplement. The global market of functional beverages has been increasing at a compound annual growth rate (CAGR) of $4.6 \%$ since 2015. Lockdowns and social distancing imposed in 2020 resulted in a $2.5 \%$ decrease, however, the market is expected to recover and grow at a CAGR of $8.07 \%$ between 2021 and 2023 (ResearchAndMarkets.com, 2020). The feasibility to incorporate nutrients and bioactive compounds result in high demand for functional beverages (Tolun and Altintas, 2019).

One of the fundamental concerns when developing functional products is whether to select the nutritional or bioactive component to maintain product stability. Desirable nutrients and bioactive compounds in 
functional beverages include antioxidants, dietary fibres, prebiotics, proteins, peptides, unsaturated fatty acids, minerals, and vitamins (Grumezescu and Holban, 2019). There are at least 8 categories of functional beverages such as dairy-based beverages, probiotic drinks, energy drinks, sports drinks, meal replacers, health and wellness, caffeinated beverages, weight management, vegetable, and fruit beverages (Tolun and Altintas, 2019). Indication of these functional beverages is either to improve the general and physical conditions or decrease the risk of the prognosis of diseases (Tolun and Altintas, 2019). Specific health benefits such as the reduced risk of cancer, improved immune system, improving physical and mental condition, anti-stress, anti -ageing, antioxidant, and anti-inflammatory properties help in the development of new products with suitable processing technologies (Shahidi and Alasalvar, 2016). Besides chemical and functional properties of the beverage, taste, texture, flavour, and appearance must also be taken into consideration to produce a safe, high quality, and market value product (Andersen et al., 2019; Wang, Mielby, Junge et al., 2019).

Marine algae, including brown algae, is a potential raw material providing health benefits from their bioactive substances (Afonso et al., 2019; Leandro et al., 2019). Notable bioactive constituents in brown alga are phlorotannins, polyphenol, phytosterol, as well as distinct marine carotenoids, namely fucoxanthin ( $\mathrm{Li}$ et al., 2018; Hakim and Patel, 2020). Efforts made to increase the number of marine algal-based product includes investigation of the nutritional composition of algal species growing in different geographical regions and seasons, improving the stability of bioactive substances, understanding the bioavailability of nutritional and bioactive compounds and their effect on human metabolism and gut microbiome (Wu et al., 2014; Wells et al., 2017; Afonso et al., 2019; Mok et al., 2018; Zhao et al., 2019).

The aim of this study is to determine the stability of brown algae, Sargassum polycystum C. Agardh extracts from species growing in West Nusa Tenggara. Extract stability, based on the antioxidant activity, was improved by the addition of sunflower oil. The resulting stabilized extract was used to enrich milk resulting in a functional dairy-based beverage. Ethanolic extract of S.polycystum contains major bioactive substances contained in brown algae, including fucoxanthin (Li et al., 2018; Hakim and Patel, 2020; Lourenço-Lopes et al., 2020). The use of sunflower oil improves the solubility of many of the less polar bioactive substances contained in the extract (Peng et al., 2011; Hakim and Patel, 2020). In addition, sunflower oil is also high in oleic acid (up to $\sim 73 \%$ ) and low in stearic acid ( $21 \%$ decrease), making this oil beneficial for human health (Garcés et al., 2009; Tupe et al., 2015; Anushree et al., 2017). Ultra-high-temperature (UHT) milk is considered microbially stable, has a relatively long shelf-life of 34-36 weeks when stored at temperatures between $4-20^{\circ} \mathrm{C}$, and is available at affordable prices (Anema, 2019; Karlsson et al., 2019). Mok et al. (2018) suggest that fucoxanthin in vitro and in vivo studies show increased fucoxanthin bioavailability in fortified milk (Mok et al., 2018). This study developed functional beverages using cold treatment $\left(4^{\circ} \mathrm{C}\right)$ to prevent degradation of bioactive compounds contained in $S$. polycystum that are sensitive to high temperature and acidic pH (Wu et al., 2014; Zhao et al., 2019). Antioxidant activity of the individual ingredients, as well as post-product formulation, was assessed and sensory evaluation was done.

\section{Materials and methods}

\subsection{Materials}

Sargassum polycystum was collected from Sumbawa district, West Nusa Tenggara in April - May 2019. Morphological identification was performed by a senior botanist and marine biologist at the Research Center for Oceanography, Indonesian Institute of Sciences. 2,2diphenyl-1-picrylhydrazyl (DPPH), methanol, DMSO were purchased from Sigma-Aldrich USA; Ethanol and distilled water were obtained as an analytical grade. All snack bar ingredients were purchased from a supermarket in South Jakarta.

\subsection{Extraction}

Sargassum polycystum was dried using an oven at $40^{\circ} \mathrm{C}$ for 48 hours. The whole dried algae were grounded using a food processor and the resulting powder was macerated in $96 \%$ Ethanol $(5: 1 \mathrm{v} / \mathrm{v})$ for $48 \mathrm{hrs}$. The extract was collected and the remaining solvent was evaporated using a vacuum rotary evaporator at $40^{\circ} \mathrm{C}$ to obtain a solid-liquid extract. The extract was stored in sealed vials and kept at $4^{\circ} \mathrm{C}$ until further analysis. The extraction process was carried out in a low light environment and apparatus.

\subsection{High-Performance Liquid Chromatography-PDA}

Analysis of fucoxanthin content was performed using High-Performance Liquid Chromatography (HPLC) (Prominance Shimadzu) equipped with LC20AD and SPD-M20A diode array. Solid-phase used was C30 YMC $(150 \mathrm{~mm} \times 4.6 \mathrm{~mm}$ ID. S-5 $\mu \mathrm{m})$. Methanol, methyl tert-butyl ether (MTBE), and aquadest HPLC grade were used as mobile phase with flow rate was maintained at $1 \mathrm{~mL} /$ minute isocratic. The sample was filtered using $0.20 \mu \mathrm{m}$ Minisart filters, then $20 \mu \mathrm{L}$ was injected on the loop-injector. Detection of 
fucoxanthin was performed using a photodiode array (190-800 nm) at $446 \mathrm{~nm}$. Fucoxanthin standard (SigmaAldrich) was used as standard.

\subsection{Antioxidant assay}

Antioxidant activity of all ingredients was measured using the DPPH method as described in a previous study (Brand-Williams et al., 1995). In brief, samples were diluted in Ethanol 96\% and diluted in the same solvent for the assay. A serially diluted sample or standard solution was mixed with $1 \mathrm{~mL}$ of $0.05 \mathrm{mM} \mathrm{DPPH}$ in Ethanol $96 \%$. The mixture was incubated for $30 \mathrm{mins}$ and in the dark. Absorbance (A1) was read at $517 \mathrm{~nm}$. The absorbance of a blank (A0, ethanol instead of extract) was recorded at the same wavelength. Scavenging ability (\%) was calculated using the following formula:

$$
\mathrm{DPPH} \text { radical scavenging activity }(\%)=\left[\frac{(\mathrm{A} 0-\mathrm{A} 1)}{\mathrm{A} 0}\right] \times 100
$$

\subsection{Beverage formulation}

The different formulation used is mentioned in Table 1. Tween- 80 was mixed gently with milk followed by stirring at $2000 \mathrm{rpm}, 100^{\circ} \mathrm{C}$ for 15 mins. Carboxymethyl cellulose (CMC) was added gradually to prevent clumping. Subsequently, sugar was added to the mixture and stirred gently. The homogenized mixture was cooled to room temperature for about $1 \mathrm{hr}$. Sargassum polycycstum extract was fortified into milk and stirred at $2000 \mathrm{rpm}$ at room temperature and in the absence of light for 30 mins. The beverage mixture was stored at $4{ }^{\circ} \mathrm{C}$ in a dark and well-sealed container.

Table 1. Composition of the beverage

\begin{tabular}{|c|c|c|c|}
\hline Ingredient & 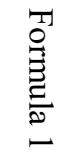 & 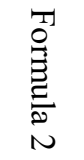 & $\begin{array}{l}\text { T } \\
\text { 䍖 } \\
\text { W }\end{array}$ \\
\hline White milk full cream (mL/cup) & 125 & 125 & 125 \\
\hline Tween-80 (g/cup) & 0.1 & 0.1 & 0.1 \\
\hline CMC (g/cup) & 0.2 & 0.2 & 0.2 \\
\hline Sunflower oil (g/cup) & 1.5 & 1.5 & 1.5 \\
\hline Sugar (g/cup) & 5 & 5 & 5 \\
\hline S. polycystum extract (g/cup) & 0.02 & 0.05 & 0.1 \\
\hline
\end{tabular}

The stability of $S$. polycystum extract in sunflower oil at $4{ }^{\circ} \mathrm{C}$ was also measured based on their antioxidant activity. DPPH assay was performed as mentioned earlier. Extract to sunflower oil ratio follows Table 1. This test was done on day- 0,3 , and 7 .

\subsection{Sensory test}

An organoleptic test was performed by 35 untrained panellists between 16 and 60 years old. Parameters observed include taste, appearance, texture, aftertaste, and overall appearance. Each parameter was scored on a scale between 1 (least acceptable) to 9 (most acceptable) (Meilgaard MC, Civille GV, 2016).

\subsection{Beverage viscosity}

The viscosity of the most favoured formula was measured and compared to unfortified milk and commercially available dairy-based beverage. Analysis was performed using Brookfield LVT-230 viscometer. Five hundred microliter of each sample was placed in a container and placed under the machine rotor. Spindel number 1 at $6 \mathrm{rpm}$ was used to measure viscosity (expressed as centipoise (cp)) after multiplying by 10 .

\subsection{Statistics}

IBM SPSS Statistics 24 Commuter software was used and data was analyzed using one-way ANOVA followed by Duncan analysis to identify the presence of significant differences between the different formulations with a 95\% confidence interval. All data were presented as average \pm standard deviation.

\section{Results and discussion}

\subsection{Sargassum polycystum extract and the presence of} fucoxanthin

Ethanolic extract of $S$. polycystum was turquoise in colour with a paste-like consistency. Qualitative analysis of fucoxanthin was performed using an HPLC and its presence was detected at $448 \mathrm{~nm}$ with a retention time of 4.43 minutes (Figure 1). This is in accordance with results obtained from fucoxanthin standard where the peak was observed at a retention time of 4.329 mins and in a previous study (Piovan et al., 2013). The concentration of fucoxanthin obtained was $0.37 \mathrm{mg} / \mathrm{g}$ (Figure 1). Sargassum polycystum C. Agardh was first identified as promising brown algae growing in West Nusa Tenggara. This study reports the presence of an important carotenoid, fucoxanthin, at a comparable concentration to Sargassum species described by Xiao et al. (2012) $(0.20 \mathrm{mg} / \mathrm{g})$ and by Renhoran et al. (2017) $(0.47 \mathrm{mg} / \mathrm{g})$. Geographical differences affect the genetic profiles of marine algae, their defence mechanism mau

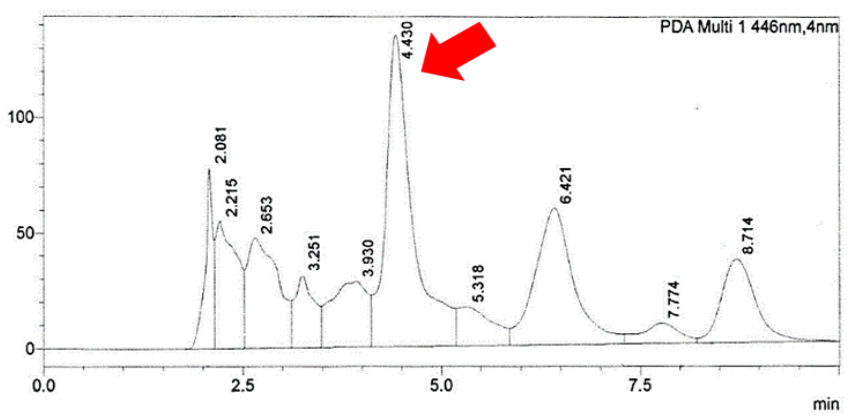

Figure 1. Chromatogram of $S$. poycystum extract and fucoxanthin was detected at Rt 4.43 
towards their living environment and hence can affect the type and amount of bioactive components (Saleh and Elatroush, 2020). Industrial-scale extraction is required (Lourenço-Lopes et al., 2020).

3.2 Antioxidant activity of Sargassum polycystum extract, sunflower oil, and its combination in beverage formula

The ability to scavenge free radicals was used to assess antioxidant activity and is stated as the concentration of a test compound to inhibit $50 \%$ of free radical $\left(\mathrm{IC}_{50}\right)$. The lower $\mathrm{IC}_{50}$ means better antioxidant activity. Ascorbic acid was used as a positive control. As seen in Table 2, sunflower oil has the highest antioxidant activity when compared to $S$. polycystum extract.

Table 2. Antioxidant activity ( $\mathrm{IC}_{50}$ value)

\begin{tabular}{cc}
\hline Ingredientt & $\mathrm{IC}_{50}(\mathrm{mg} / \mathrm{mL})$ \\
\hline Ascorbic acid & $18 \times 10^{-4} \pm 0.01^{\mathrm{a}}$ \\
S. polycystum extract & $0.16 \pm 0.02^{\mathrm{b}}$ \\
Sunflower oil & $0.06 \pm 0.08^{\mathrm{c}}$ \\
\hline
\end{tabular}

Values are presented as mean \pm standard deviation. Values with different superscript are significantly different $(\mathrm{P}<0.05)$.

Antioxidant activity of the extract results from the presence of phlorotannin (Boi et al., 2016; Cuong et al., 2016) and fucoxanthin (Sachindra et al., 2007; Miyashita et al., 2020) - prominent antioxidants commonly found in Sargassum species. The phenolic pool in phlorotannin contributes to the hydrogen donating ability, exhibits high free radical scavenging activity, especially against $\mathrm{DPPH}^{\circ}$ and $\mathrm{O}_{2}{ }^{\circ}$. Polyphenols with multiple hydroxyl groups also exhibit high redox potential, protecting from free radicals formed as by-products of mitochondrial metabolism (Mathew et al., 2015). Fucoxanthin, on the other hand, exhibits antioxidant activity due to the presence of conjugated bonds that are able to stabilize free radicals (Peng et al., 2011; Miyashita et al., 2020). Similar to the composition of olive oil, sunflower oil is rich in oleic acid and possesses a strong ability to scavenge free radicals, including DPPH (Xiang et al., 2017). Oleic acid also increases the Superoxide Dismutase (SOD) activity of cadmium-treated rat organs and reduces the level of superoxide radical $\mathrm{O}^{2-}$ (Wang, Zhang, Fang et al., 2019). Vitamin E, often contained in sunflower oil can synergistically increase antioxidant activity (Garcés et al., 2009; Aldini et al., 2010).

Antioxidant activity of $S$. polycystum in combination with sunflower oil in formulation most-favoured by the panellists, formula 2 was also measured (Figure 2). The ability of $S$. polycystum extract to maintain antioxidant activity was higher than unfortified extracts (control) and the activity was maintained up to day-7 (Figure 2).

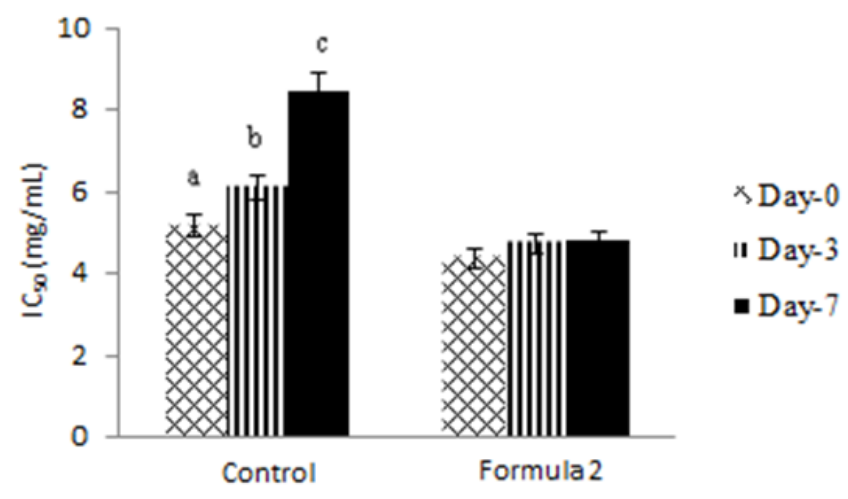

Figure 2. Antioxidant activity of formula 2 (with sunflower oil and extract) and control (without sunflower oil and extract). Bars with different notations are significantly different $(\mathrm{P}<0.05)$.

Combining S. polycystum extract with sunflower oil was able to maintain antioxidant activity. Further analysis is required to pinpoint the single bioactive compound contained in each ingredient that is responsible for this activity (Pérez-Gálvez et al., 2000; Sunil et al., 2015; Susanti et al., 2020). The formulation of beverage at $4{ }^{\circ} \mathrm{C}$ maintained the stability of bioactive compounds present in the extract and prevented oxidation of sunflower oil (Guiotto et al., 2014). In addition, the presence of bioactive compounds in sunflower oil such as oleic acid and tocopherol may have also maintained antioxidant activity (Rao et al., 2007; Anushree et al., 2017; Wang et al., 2019).

\subsection{Beverage formulation and sensory test}

A combination of extract and sunflower oil was applied to develop a beverage with additional increased antioxidant activity. The panellists rated formula 2 as the best formula (Table 3). Although formula 3 contained the highest concentration of extract, it wasn't the most favoured amongst panellists. This can be attributed to the bitter taste that may have been caused by the Sargassum extract (Chengkui and Junfu, 1984; Liu et al., 2012; Encyclopedia, 2021). Tween 80 could have also contributed to the bitter taste (Rowe et al., 2009).

Table 3. Sensory analysis of formula 1, 2, and 3

\begin{tabular}{llll}
\hline Attribute & Formula 1 & Formula 2 & Formula 3 \\
\hline Color & $5.60 \pm 0.87^{\mathrm{a}}$ & $5.85 \pm 1.25^{\mathrm{a}}$ & $5.75 \pm 1.03^{\mathrm{a}}$ \\
Aroma & $4.60 \pm 0.87^{\mathrm{a}}$ & $4.18 \pm 0.81^{\mathrm{a}}$ & $4.40 \pm 0.81^{\mathrm{a}}$ \\
Taste & $6.38 \pm 1.20^{\mathrm{a}}$ & $6.27 \pm 1.42^{\mathrm{a}}$ & $3.83 \pm 1.01^{\mathrm{b}}$ \\
Viscosity & $5.28 \pm 1.06^{\mathrm{a}}$ & $5.18 \pm 1.11^{\mathrm{a}}$ & $5.15 \pm 1.33^{\mathrm{a}}$ \\
Aftertaste & $5.28 \pm 1.22^{\mathrm{a}}$ & $5.45 \pm 1.50^{\mathrm{a}}$ & $3.33 \pm 1.00^{\mathrm{b}}$ \\
Overall & $5.65 \pm 0.85^{\mathrm{a}}$ & $6.5 \pm 1.04^{\mathrm{b}}$ & $4.23 \pm 0.93^{\mathrm{c}}$ \\
\hline
\end{tabular}

Values are presented as mean \pm standard deviation. Values with different superscript within the same row are significantly different $(\mathrm{P}<0.05)$. 


\subsection{Viscosity test}

Formula 2 has a viscosity of $135 \mathrm{cp}$, while the control formula that was not fortified with Sargassum has a viscosity value of $130 \mathrm{cp}$, and the commercial product was $359 \mathrm{cp}$. No significant difference was found between formula 2 and the control $(p>0.05)$. The surfactant agent used was able to improve viscosity while still maintaining organoleptic scores (Figure 3). In this study, CMC was used as a thickening agent, surfactant enhancer, as well as a stabilizer. CMC has been widely used in the field of food production (Arancibia et al., 2013; Meng et al., 2018). The addition of CMC increases viscosity to desirable rheological and consistency (Arancibia et al., 2013).

\section{Conclusion}

Sargassum polycystum extract and sunflower oil are known to have individual antioxidant activity and are able to maintain this even when combined. This combination resulted in a dairy-based beverage with acceptable sensory attributes. This study presents the application of underexplored brown algae found in remote areas as a functional food that is cheap, safe, stable, and healthy. A study on product variation involving the greater scope of sensory evaluation and industrial scaling up is necessary.

\section{Conflict of interest}

The authors declare no conflict of interest.

\section{Acknowledgments}

This research was funded by Atma Jaya Catholic University of Indoensia.

\section{References}

Afonso, N.C., Catarino, M.D., Silva, A.M.S. and Cardoso, S.M. (2019). Brown macroalgae as valuable food ingredients. Antioxidants, 8(9), 365. https://doi.org/10.3390/antiox8090365

Aldini, G., Yeum, K., Niki, E. and Russel, R. (2010). Biomarkers for antioxidant defensive and oxidative damage. United Kingdom: Wiley-Blackwell Publishing Ltd. https:// doi.org/10.1002/9780813814438

Andersen, B.V., Brockhoff, P.B. and Hyldig, G. (2019). The importance of liking of appearance, -odour, taste and -texture in the evaluation of overall liking. A comparison with the evaluation of sensory satisfaction. Food Quality and Preference, 71, 228232. https://doi.org/10.1016/j.foodqual.2018.07.005

Anema, S.G. (2019). Age Gelation, Sedimentation, and
Creaming in UHT Milk: A Review. Comprehensive Reviews in Food Science and Food Safety, 18(1), 140-166. https://doi.org/10.1111/1541-4337.12407

Anushree, S., André, M., Guillaume, D. and Frédéric, F. (2017). Stearic sunflower oil as a sustainable and healthy alternative to palm oil. A review. Agronomy for Sustainable Development, 37(3), 1-10. https:// doi.org/10.1007/s13593-017-0426-x

Arancibia, C., Bayarri, S. and Costell, E. (2013). Comparing carboxymethyl cellulose and starch as thickeners in oil/water emulsions. Implications on rheological and structural properties. Food Biophysics, 8(2), 122-136. https://doi.org/10.1007/ s1 1483-013-9287-2

Boi, V.N., Cuong, D.X. and Khanh Vinh, P.T. (2016). Effects of extraction conditions over the phlorotannin content and antioxidant activity of extract from brown algae Sargassum serratum (Nguyen Huu Dai 2004). Free Radicals and Antioxidants, 7(1), 115-122. https://doi.org/10.5530/ fra.2017.1.17

Brand-Williams, W., Cuvelier, M.E. and Berset, C. (1995). Use of a free radical method to evaluate antioxidant activity. LWT - Food Science and Technology, 28(1), 25-30. https://doi.org/10.1016/ S0023-6438(95)80008-5

Chengkui, Z. and Junfu, Z. (1984). Chinese seaweeds in herbal medicine. In Bird, C.J. and Ragan, M.A. (Eds.) Eleventh International Seaweed Symposium. Developments in Hydrobiology. Vol. 22, p. 152154. Dordrecht, Netherlands: Springer. https:// doi.org/10.1007/978-94-009-6560-7_24

Cuong, D.X., Boi, V.N., Van, T.T.T. and Hau, L.N. (2016). Effect of storage time on phlorotannin content and antioxidant activity of six Sargassum species from Nhatrang Bay, Vietnam. Journal of Applied Phycology, 28(1), 567-572. https:// doi.org/10.1007/s10811-015-0600-y

Encyclopedia. (2021). Sargassum Seaweed. Gale Encyclopedia of Alternative Medicine. Retreived from Encyclopedia website: https:// www.encyclopedia.com/medicine/encyclopediasalmanacs-transcripts-and-maps/sargassum-seaweed

Garcés, R., Martínez-Force, E., Salas, J.J. and VenegasCalerón, M. (2009). Current advances in sunflower oil and its applications. Lipid Technology, 21(4), 7982. https://doi.org/10.1002/lite.200900016

Grumezescu, A. and Holban, A. (2019). Functional and Medicinal Beverages. Volume 11: The Science of Beverages. USA: Academic Press. https:// doi.org/10.1016/B978-0-12-816397-9.00007-8

Guiotto, E.N., Ixtaina, V.Y., Nolasco, S.M. and Tomás, 
M.C. (2014). Effect of storage conditions and antioxidants on the oxidative stability of sunflowerchia oil blends. Journal of the American Oil Chemists' Society, 91(5), 767-776. https:// doi.org/10.1007/s11746-014-2410-9

Hakim, M.M. and Patel, I.C. (2020). A review on phytoconstituents of marine brown algae. Future Journal of Pharmaceutical Sciences, 6(1), 1-11. https://doi.org/10.1186/s43094-020-00147-6

Iwatani, S. and Yamamoto, N. (2019). Functional food products in Japan: A review. Food Science and Human Wellness, 8(2), 96-101. https:// doi.org/10.1016/j.fshw.2019.03.011

Jędrusek-Golińska, A., Górecka, D., Buchowski, M., Wieczorowska-Tobis, K., Gramza-Michałowska, A. and Szymandera-Buszka, K. (2020). Recent progress in the use of functional foods for older adults: A narrative review. In Comprehensive Reviews in Food Science and Food Safety, p. 835-856. United Kingdom: Blackwell Publishing Inc. https:// doi.org/10.1111/1541-4337.12530

Karlsson, M.A., Langton, M., Innings, F., Malmgren, B., Höjer, A., Wikström, M. and Lundh, Å. (2019). Changes in stability and shelf-life of ultra-high temperature treated milk during long term storage at different temperatures. Heliyon, 5(9), e02431. https://doi.org/10.1016/j.heliyon.2019.e02431

Leandro, A., Pereira, L. and Gonçalves, A.M.M. (2019). Diverse applications of marine macroalgae. Marine Drugs, 18(1), $17 . \quad$ https://doi.org/10.3390/ md18010017

Li, Y., Fu, X., Duan, D., Xu, J. and Gao, X. (2018). Comparison study of bioactive substances and nutritional components of brown algae Sargassum fusiforme strains with different vesicle shapes. Journal of Applied Phycology, 30(6), 3271-3283. https://doi.org/10.1007/s10811-018-1543-x

Liu, L., Heinrich, M., Myers, S. and Dworjanyn, S.A. (2012). Towards a better understanding of medicinal uses of the brown seaweed Sargassum in Traditional Chinese Medicine: A phytochemical and pharmacological review. Journal of Ethnopharmacology, 142(3), 591-619. https:// doi.org/10.1016/j.jep.2012.05.046

Lourenço-Lopes, C., Garcia-Oliveira, P., Carpena, M., Fraga-Corral, M., Jimenez-Lopez, C., Pereira, A.G., Prieto, M.A. and Simal-Gandara, J. (2020). Scientific approaches on extraction, purification and stability for the commercialization of fucoxanthin recovered from brown algae. Foods, 9(8), 1113. https://doi.org/10.3390/foods9081113

Mathew, S., Abraham, T.E. and Zakaria, Z.A. (2015).
Reactivity of phenolic compounds towards free radicals under in vitro conditions. Journal of Food Science and Technology, 52(9), 5790-5798. https:// doi.org/10.1007/s13197-014-1704-0

Meilgaard, M.C. and Civille GV, C.B. (2016). Sensory evaluation techniques. 5th ed. USA: CRC Press.

Meng, Z., Qi, K., Guo, Y., Wang, Y. and Liu, Y. (2018). Effects of thickening agents on the formation and properties of edible oleogels based on hydroxypropyl methyl cellulose. Food Chemistry, 246, 137-149. https://doi.org/10.1016/j.foodchem.2017.10.154

Miyashita, K., Beppu, F., Hosokawa, M., Liu, X. and Wang, S. (2020). Nutraceutical characteristics of the brown seaweed carotenoid fucoxanthin. Archives of Biochemistry and Biophysics, 686 . https:// doi.org/10.1016/j.abb.2020.108364

Mok, I.K., Lee, J.K., Kim, J.H., Pan, C.H. and Kim, S.M. (2018). Fucoxanthin bioavailability from fucoxanthin-fortified milk: In vivo and in vitro study. Food Chemistry, 258, 79-86. https:// doi.org/10.1016/j.foodchem.2018.03.047

Ozen, A.E., Pons, A. and Tur, J.A. (2012). Worldwide consumption of functional foods: a systematic review. Nutrition Reviews, 70(8), 472-481. https:// doi.org/10.1111/j.1753-4887.2012.00492.x

Peng, J., Yuan, J.P., Wu, C.F. and Wang, J.H. (2011). Fucoxanthin, a marine carotenoid present in brown seaweeds and diatoms: Metabolism and bioactivities relevant to human health. Marine Drugs, 9(10), 1806 -1828. https://doi.org/10.3390/md9101806

Pérez-Gálvez, A., Garrido-Fernández, J. and MínguezMosquera, M.I. (2000). Effect of high-oleic sunflower seed on the carotenoid stability of ground pepper. Journal of the American Oil Chemists' Society, 77(1), 79-83. https://doi.org/10.1007/ s11746-000-0012-x

Piovan, A., Seraglia, R., Bresin, B., Caniato, R. and Filippini, R. (2013). Fucoxanthin from undaria pinnatifida: Photostability and coextractive effects. Molecules, 18(6), 6298-6310. https:// doi.org/10.3390/molecules18066298

Rao, A.R., Sarada, R. and Ravishankar, G.A. (2007). Stabilization of astaxanthin in edible oils and its use as an antioxidant. Journal of the Science of Food and Agriculture, 87(6), 957-965. https://doi.org/10.1002/ jsfa. 2766

Renhoran, M., Noviendri, D., Setyaningsih, I. and Uju, U. (2017). Extraction and purification of fucoxanthin from Sargassum sp. as anti-acne. Jurnal Pengolahan Hasil Perikanan Indonesia, 20, 370-379. https:// doi.org/10.17844/jphpi.v20i2.18105

ResearchAndMarkets.com. (2020). Global Functional 
Beverages Market Report 2020-30: COVID-19 Growth and Change. Retreived from businesswire website: https://www.businesswire.com/news/ home/20200608005232/en/Global-Functional-

Beverages-Market-Report-2020-30-COVID-19-

Growth-and-Change---ResearchAndMarkets.com

Rowe, R., Sheskey, P.J. and Quinn, M.E. (2009). Handbook of Pharmaceutical Excipients. 6th ed. USA: Amer Pharmacists Association.

Sachindra, N.M., Sato, E., Maeda, H., Hosokawa, M., Niwano, Y., Kohno, M. and Miyashita, K. (2007). Radical scavenging and singlet oxygen quenching activity of marine carotenoid fucoxanthin and its metabolites. Journal of Agricultural and Food Chemistry, 55(21), 8516-8522. https:// doi.org/10.1021/jf071848a

Saleh, A. and Elatroush, H. (2020). Impact of different geographical locations on genetic variation and phytochemical constituents of two medicinal marine algae. Taeckholmia, 40(1), 12-26. https:// doi.org/10.21608/taec.2020.21902.1012

Shahidi, F. and Alasalvar, C. (2016). Handbook of Functional Beverages and Human Health. USA: CRC Press.

Sunil, L., Srinivas, P., Prasanth Kumar, P.K. and Gopala Krishna, A.G. (2015). Oryzanol as natural antioxidant for improving sunflower oil stability. Journal of Food Science and Technology, 52(6), 3291-3299. https://doi.org/10.1007/s13197-0141385-8

Susanti, Y., Purba, A.V. and Rahmat, D. (2020). Nilai antioksidan dan Spf dari kombinasi minyak biji wijen (Sesamum indicum L.) dan minyak biji bunga matahari (Helianthus annuus L.). Majalah Farmaseutik, 16(1), 107-110. https:// doi.org/10.22146/farmaseutik.v16i1.52243

Tolun, A. and Altintas, Z. (2019). Medicinal properties and functional components of beverages. In Grumezescu, A.M. and Holban, A.M. (Eds.), Functional and Medicinal Beverages. Volume 11: The Science of Beverages, p. 235-284. USA: Academic Press. https://doi.org/10.1016/B978-0-12816397-9.00007-8

Tupe, R.S., Sankhe, N.M., Shaikh, S.A., Phatak, D.V., Parikh, J.U., Khaire, A.A. and Kemse, N.G. (2015). Aqueous extract of some indigenous medicinal plants inhibits glycation at multiple stages and protects erythrocytes from oxidative damage-an in vitro study. Journal of Food Science and Technology, 52(4), 1911-1923. https:// doi.org/10.1007/s13197-013-1211-8

Vicentini, A., Liberatore, L. and Mastrocola, D. (2016).
Functional foods: Trends and development of the global market. Italian Journal of Food Science, 28 (2), 338-351. https://doi.org/10.14674/1120-1770/ ijfs.v211

Wang, Q.J., Mielby, L.A., Junge, J.Y., Bertelsen, A.S., Kidmose, U., Spence, C. and Byrne, D.V. (2019). The role of intrinsic and extrinsic sensory factors in sweetness perception of food and beverages: A review. Foods, 8(6), 211. https://doi.org/10.3390/ foods 8060211

Wang, J., Zhang, Y., Fang, Z., Sun, L., Wang, Y., Liu, Y., Xu, D., Nie, F. and Gooneratne, R. (2019). Oleic acid alleviates cadmium-induced oxidative damage in rat by its radicals scavenging activity. Biological Trace Element Research, 190(1), 95-100. https:// doi.org/10.1007/s12011-018-1526-4

Wells, M.L., Potin, P., Craigie, J.S., Raven, J.A., Merchant, S.S., Helliwell, K.E., Smith, A.G., Camire, M.E. and Brawley, S.H. (2017). Algae as nutritional and functional food sources: revisiting our understanding. Journal of Applied Phycology, 29 (2), 949-982. https://doi.org/10.1007/s10811-0160974-5

Wu, H.Y., Lim, S.J., Mustapha, W.A.W., Maskat, M.Y. and Said, M. (2014). Characterisation and stability of pigments extracted from Sargassum binderi obtained from Semporna. Sains Malaysiana, 43(9), 1345 1354.

Xiang, C., Xu, Z., Liu, J., Li, T., Yang, Z. and Ding, C. (2017). Quality, composition, and antioxidant activity of virgin olive oil from introduced varieties at Liangshan. LWT - Food Science and Technology, 78, 226-234. https://doi.org/10.1016/ j.lwt.2016.12.029

Xiao, X., Si, X., Yuan, Z., Xu, X. and Li, G. (2012). Isolation of fucoxanthin from edible brown algae by microwave-assisted extraction coupled with highspeed countercurrent chromatography. Journal of Separation Science, 35(17), 2313-2317. https:// doi.org/10.1002/jssc.201200231

Zhao, D., Yu, D., Kim, M., Gu, M.Y., Kim, S.M., Pan, C.H., Kim, G.H. and Chung, D. (2019). Effects of temperature, light, and $\mathrm{pH}$ on the stability of fucoxanthin in an oil-in-water emulsion. Food Chemistry, 291, 87-93. https://doi.org/10.1016/ j.foodchem.2019.04.002 